\title{
Non-esterified fatty acids regulate lipid and glucose oxidation and glycogen synthesis in healthy man
}

\author{
P. Ebeling, V.A. Koivisto \\ Second Department of Medicine, Helsinki University Hospital, Helsinki, Finland
}

\begin{abstract}
Summary We examined the interrelationship of lipid and glucose metabolism in the basal state and during insulin stimulus in 19 healthy men $(27 \pm 2$ years, body mass index $23.6 \pm 0.6 \mathrm{~kg} / \mathrm{m}^{2}$ ). In each subject, we performed a 4 -h euglycaemic $(5.3 \pm 0.1 \mathrm{mmol} / \mathrm{l})$ hyperinsulinaemic $(647 \pm 21 \mathrm{pmol} / \mathrm{l})$ insulin clamp with indirect calorimetry in the basal state and during insulin infusion, and muscle biopsies before and at the end of the clamp. In the basal state, serum non-esterified fatty acid levels correlated directly with lipid oxidation $(r=0.56, p<0.05)$ and indirectly with glucose oxidation $(r=-0.80, p<0.001)$. Lipid and glucose oxidation rates were inversely related in the basal state $(r=$ $-0.47, p<0.05)$ and during insulin infusion $(r=-0.65$, $p<0.01$ ). Basal lipid oxidation and glycogen synthase total activity correlated inversely $(r=-0.54, p<0.05)$. Lipid oxidation both in the basal state $(r=-0.61$, $p<0.01)$ and during insulin infusion $(r=-0.62$, $p<0.05$ ) was inversely related to muscle glycogen content after the insulin clamp. Fasting plasma triglyceride
\end{abstract}

concentration correlated directly to fasting insulin $(r=0.55, p<0.05)$ and C-peptide $(r=0.50, p<0.03)$ concentrations and inversely to non-oxidative glucose disposal rate at the end of clamp $(r=-0.54, p<0.05)$. In conclusion: 1) Serum non-esterified fatty acid concentration enhances lipid and reduces glucose oxidation. 2) Lipid oxidation is inversely related to total glycogen synthase activity. 3) Lipid oxidation both in the basal state and during insulin stimulus correlates inversely with muscle glycogen content after insulin infusion. 4) Even in normotriglyceridaemic subjects, plasma triglycerides reduce insulin-stimulated non-oxidative glucose disposal. These data suggest that serum non-esterified fatty acids in physiologic concentrations have an important role in the regulation of lipid and glucose oxidation as well as glucose storage as glycogen. [Diabetologia (1994) 37: 202-209]

Key words Fatty acid metabolism, insulin sensitivity, glycogen, glycogen synthase, lipoproteins.
The interrelationship of glucose and fatty acid metabolism was proposed 30 years ago by Randle and coworkers [1]. They introduced the concept of glucose fatty acid cycle by demonstrating an inhibition of glucose uptake by non-esterified fatty acids (NEFA) in the perfused rat heart [1]. Since reduced glucose uptake and insulin resistance is observed in a number of pathologic conditions, such as in obesity [2], Type 2

Received: 2 June 1993

and in revised form: 27 August 1993

Corresponding author: Dr. V.A.Koivisto, Second Department of Medicine, University of Helsinki, Haartmaninkatu 4, SF00290 Helsinki, Finland (non-insulin-dependent) diabetes mellitus [3] or first degree relatives of Type 2 diabetic patients [4] or in hypertensive patients [5], much investigative interest has been focused on the importance of NEFA as a factor reducing glucose disposal under these conditions. However, in healthy subjects the contribution of NEFA to the regulation of glucose disposal and its metabolism along oxidative or non-oxidative pathways is less well known. While in the basal state elevated NEFA concentration increases forearm glucose uptake [6], during hyperinsulinaemia high NEFA concentration reduces glucose uptake due to a decrease in glucose oxidation [6]. The reduction in insulin-stimulated glucose disposal by high serum NEFA concentration occurs both in the myocardial and skeletal 
muscle [7]. These data do not, however, directly apply to normal physiology, where serum NEFA concentrations are lower than those in the previous studies, in which Intralipid and heparin infusions have been employed [6-8]. Considering the mechanisms by which physiologic NEFA concentrations can influence glucose disposal, it is important to know its effect both on glucose oxidation and storage. Changes in the activity of glycogen synthase (EC 2.4.1.11), caused either by allosteric regulators or covalent modification regulate glycogen synthesis [9]. Variations in glycogen synthase activity have been been observed in parallel with the changes in body sensitivity to insulin. A reduction in the glycogen synthase activity has been reported in Type 2 diabetic patients [10] and in their insulin resistant first-degree relatives [11]. On the other hand, in athletes with higher than normal insulin sensitivity and non-oxidative glucose disposal, muscle glycogen synthase activity is elevated [12]. To what extent serum NEFA in physiologic concentrations and fat oxidation contribute to the regulation of glucose oxidation or storage, and glycogen synthase activity is not known. Consequently, the present study was designed to examine the interrelationship of serum NEFA and fat oxidation and glucose oxidation, storage and glycogen synthase activity in healthy man.

\section{Subjects and methods}

Nineteen healthy male subjects (age $26.8 \pm 1.3$ years, BMI $23.6 \pm 0.6 \mathrm{~kg} / \mathrm{m}^{2}, \mathrm{VO}_{2 \max } 50.5 \pm 2.0 \mathrm{ml} \cdot \mathrm{kg}^{-1} \cdot \mathrm{min}^{-1}$ ) participated in the study. The subjects were asked to ingest at least $250 \mathrm{~g}$ carbohydrate per day and not to perform any intensive exercise for 2 days before the study. The purpose, nature and possible risks of the study were explained to all subjects before informed consent was obtained. The study protocol was approved by the Ethical Committee of the Helsinki University Hospital.

\section{Design}

We performed a 240-min euglycaemic insulin clamp in each subject. Indirect calorimetry was determined once before and three times during the clamp. Whole body glucose disposal was determined throughout the study, and muscle biopsy was taken before and at the end of the clamp. In these biopsies from $m$. quadriceps vastus lateralis we determined muscle glycogen content and glycogen synthase activity.

Whole body glucose disposal was determined using the euglycaemic insulin clamp technique, as previously described $[13,14]$. After an overnight fast, two catheters were inserted: one in an antecubital vein for the infusion of insulin and glucose, and the other into a heated $\left(60^{\circ} \mathrm{C}\right)$ hand vein for the sampling of arterialized blood. Insulin (Actrapid Human; Novo Nordisk A/S, Copenhagen, Denmark) was infused at a primed continuous rate (9 $\left.\mathrm{nmol}(1.5 \mathrm{mU}) \cdot \mathrm{kg}^{-1} \cdot \mathrm{min}^{-1}\right)$ for $240 \mathrm{~min}$. Plasma glucose was maintained at the fasting level with $20 \%$ glucose infused at a variable rate based on plasma glucose determinations from the arterialized blood at 5-10 min intervals. Since hepatic glucose production is totally suppressed at even lower insulin infusion rates than employed here [15], the glucose infusion rate corrected for changes in plasma glucose concentration equals the rate of glucose disposal.

Oxidative glucose disposal and lipid oxidation were determined with indirect calorimetry (Deltatrac Metabolic Monitor, Datex, Helsinki, Finland) in the basal state and three times (between 50$80 \mathrm{~min}, 130-160 \mathrm{~min}$ and 210-240 min) during the insulin clamp study, as previously described by our laboratory $[16,17]$. In the analysis, the mean value of the three determinations from eachindividual is taken to represent the glucose oxidation rate during the insulin infusion. The constants to calculate glucose and lipid oxidation from respiratory exchange data have been given previously [18]. Non-oxidative glucose disposal (storage) is defined as the difference between total and oxidative glucose disposal.

\section{Muscle biopsies}

We performed a percutaneous muscle biopsy $(100-150 \mathrm{mg})$ with a Bergström needle under local anaesthesia (1\% lidocaine) $15 \mathrm{~min}$ before and at the end of the 240 -min insulin clamp study. The samples were obtained from $\mathrm{m}$. quadriceps vastus lateralis from opposite sites before and after the study. The specimen was removed from muscle with suction by a syringe attached to the needle, and the needle was immediately emptied into liquid $\mathrm{N}_{2}$. With this procedure, the muscle sample can be frozen in less than $5 \mathrm{~s}$ after removal. The specimens were stored in liquid $\mathrm{N}_{2}$ until analysed.

Muscle glycogen. The muscle samples were freeze-dried and dissected free from connective tissue and blood. The muscle was powdered, divided into two lots and weighed. Three to five $\mathrm{mg}$ of muscle powder was extracted with $\mathrm{KOH}$, neutralized, glycogen was hydrolysed with amyloglycosidase, and the liberated glucose was analysed with the glucose oxidase method. Glycogen concentration is expressed as millimoles per kilogram of dry muscle $[11,19]$.

Glycogen synthase activity. For the determination of glycogen synthase activity, muscle samples were homogenized at $+4^{\circ} \mathrm{C}$. Homogenate samples and blanks were incubated in UDP-glucose $(50 \mathrm{mmol} / 1)$ and glucose 6-phosphate (G 6-P, 0.1 and $10.0 \mathrm{mmol} / \mathrm{l}$ ) at $37^{\circ} \mathrm{C}$ for $15 \mathrm{~min}$. Reaction was stopped at $100^{\circ} \mathrm{C}$ in $2 \mathrm{~min}$. The reaction was continued at room temperature in the medium containing in final concentrations $30 \mathrm{mmol} / 1$ glycylglycine, $0.1 \mathrm{mmol} / 1$ phosphoenolpyruvate, $70 \mathrm{mmol} / 1 \mathrm{KCl}$, $15 \mathrm{mmol} / 1 \mathrm{MgCl}_{2}, 10 \mathrm{mmol} / \mathrm{l}$ hydrazinehydrate, $2.5 \mathrm{U} / \mathrm{ml}$ lactatedehydrogenase together with $30 \mu \mathrm{mol} / 1 \mathrm{NADH}$. One $\mathrm{ml}$ of the solution was transferred to cuvettes, $0.2 \mathrm{U} / \mathrm{ml}$ pyruvate kinase was added and the $\mathrm{NAD}^{+}$production was measured by fluorometry $[11,19]$. This method determines the production of uridine diphosphate (UDP) from the incorporation of UDP-glucose in glycogen. The final concentration of UDP-glucose in the solution was $7.1 \mathrm{mmol} / \mathrm{l}$. The assay was linear for protein concentration in the homogenate. Protein concentration was determined according to Lowry et al. [20]. The enzyme activity as determined at $0.1 \mathrm{mmol} / 1 \mathrm{G} \mathrm{6-P}$ is called glycogen synthase activity, the one at $10 \mathrm{mmol} / \mathrm{h} \mathrm{G}$ 6-P is called total glycogen synthase activity, and the ratio of the two $(0.1 / 10 \mathrm{mmol} / \mathrm{G} \mathrm{G} \mathrm{6-P)}$ is called glycogen synthase fractional activity. We were unable to measure muscle glycogen content in one subject before and in another after the clamp, and glycogen synthase activity in the same four subjects either before or after the clamp, since the muscle sample size was too small.

Maximal aerobic power $\left(\mathrm{VO}_{2 \max }\right)$ was measured using a cycle ergometer exercise test in a stepwise manner (Bosch ERG 220; 
Robert Bosch, GmbH, Berlin, Germany). Maximal aerobic power was defined as $\mathrm{VO}_{2}$ of the highest 30 s of the exercise [21].

Other determinations. Glucose in the plasma and glycogen assays were determined with a glucose oxidase method using a Beckman glucose analyzer (Beckman Instruments, Fullerton, Calif., USA). Serum insulin was measured by a double antibody radioimmunoassay (Pharmacia, Uppsala, Sweden) [22]. Serum C-peptide concentration was determined with radioimmunoassay [23]. NEFA concentrations in serum were determined by using the fluorometric method of Miles et al. [24]. Total plasma cholesterol, plasma HDL cholesterol and plasma triglyceride concentrations were measured before the insulin infusion, at $180 \mathrm{~min}$ and at $240 \mathrm{~min}$ during the insulin infusion. Plasma cholesterol concentration was determined enzymatically [25]. After precipitation of VLDL and LDL [26] the measurements of plasma HDL cholesterol were performed enzymatically [25]. Plasma LDL cholesterol was calculated using the Friedewald formula [27]. Plasma triglyceride concentration was measured enzymatically [28].

\section{Statistical analysis}

Wilcoxon-Pratt's test was used in the calculations between paired items. The correlation analysis was done with Spearman's test. $P$ values less than 0.05 were considered significant. The results are given as mean \pm SEM.

\section{Results}

Glucose, insulin and C-peptide. The fasting plasma glucose concentration $(5.8 \pm 0.1 \mathrm{mmol} / \mathrm{l})$ decreased slightly during the first $30 \mathrm{~min}$ of insulin infusion, but remained unchanged thereafter at a mean level of $5.3 \pm 0.1 \mathrm{mmol} / 1$. Serum insulin concentration increased from the basal value of $18.3 \pm 1.4 \mathrm{pmol} / 1$ to $646.8 \pm 20.2 \mathrm{pmol} / \mathrm{l}$ after 30 -min insulin infusion and remained unchanged thereafter. Serum fasting C-peptide concentration was $0.48 \pm 0.04 \mathrm{nmol} / \mathrm{l}$.

Non-esterified fatty acids. Fasting NEFA concentration $(452 \pm 37 \mu \mathrm{mol} / \mathrm{l})$ decreased rapidly during the first $30 \mathrm{~min}$, reaching the final concentration of $108 \pm 6 \mu \mathrm{mol} / 1$ at $240 \mathrm{~min}(p<0.001 \mathrm{vs}$ basal). Fasting NEFA concentration correlated with the concentration at $30 \mathrm{~min}(r=0.48, p<0.05)$, but not with values thereafter. The NEFA concentration at $240 \mathrm{~min}$ correlated significantly with all previous concentrations during insulin infusion $(r=0.71-0.89, p<0.001$ for all $)$.

Lipids and lipoproteins. Mean fasting total cholesterol concentration was $4.4 \pm 0.2 \mathrm{mmol} / \mathrm{l}$, HDL cholesterol $1.2 \pm 0.1 \mathrm{mmol} / \mathrm{l}, \mathrm{LDL}$ cholesterol $2.8 \pm 0.2 \mathrm{mmol} / \mathrm{l}$ and triglycerides $0.8 \pm 0.1 \mathrm{mmol} / 1$. Fasting plasma triglyceride concentration was related to both fasting insulin $(r=0.55, p<0.02)$ and C-peptide concentrations $(r=0.50, p<0.03)$. While triglycerides declined by $180 \mathrm{~min}$ of insulin infusion (to $0.6 \pm 0.1 \mathrm{mmol} / \mathrm{l}$, $p<0.001$ ), plasma total and LDL cholesterol decreased (to $4.1 \pm 0.2 \mathrm{mmol} / 1$ and $2.4 \pm 0.2 \mathrm{mmol} / 1$, re-


Fig.1 a-d. The individual values of serum HDL cholesterol (a), LDL cholesterol (b), total cholesterol (c) and triglyceride (d) concentrations in the fasting state and after 180 - and 240 -min insulin infusion

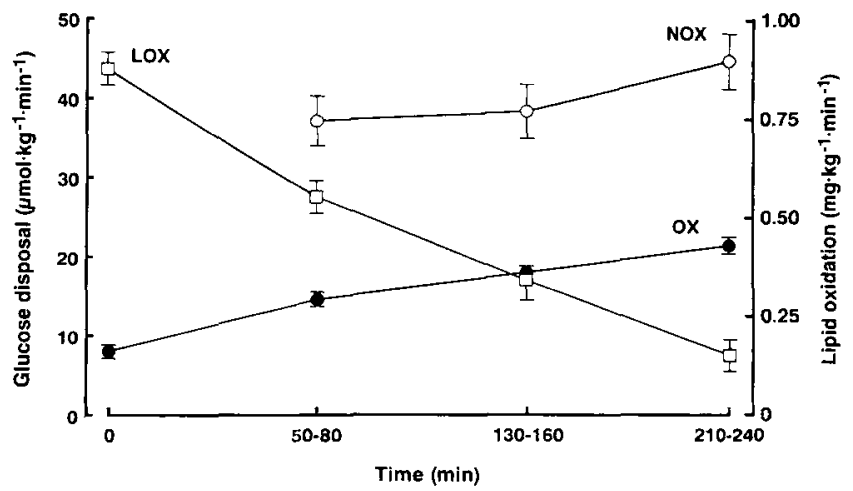

Fig. 2. The rate of oxidative (OX) and non-oxidative (NOX) glucose disposal and lipid oxidation (LOX). Glucose and lipid oxidation were determined both in the basal state and in three 30-min periods of insulin infusion, non-oxidative glucose disposal was determined only during insulin infusion

spectively, $p<0.01$ ) and HDL cholesterol increased (to $1.4 \pm 0.1 \mathrm{mmol} / \mathrm{l}, p<0.01$ ) however, not until during the last hour of insulin infusion (Fig. 1). The rise in plasma HDL cholesterol was related to the basal insulin $(r=0.55, \quad p<0.05)$ and C-peptide concentration $(r=0.55, p<0.05)$.

Glucose disposal. Insulin infusion increased glucose oxidation rate 2.7 -fold (from $8.0 \pm 0.6 \mu \mathrm{mol} \cdot \mathrm{kg}^{-1} \cdot \mathrm{min}^{-1}$ to $21.6 \pm 1.1 \mu \mathrm{mol} \cdot \mathrm{kg}^{-1} \cdot \mathrm{min}^{-1} p<0.001$, Fig. 2). During insulin infusion from 50 to $240 \mathrm{~min}$, non-oxidative glucose disposal increased from $37.3 \pm 3.3 \mu \mathrm{mol} \cdot \mathrm{kg}^{-1}$. $\min ^{-1}$ to $45.0 \pm 3.3 \mu \mathrm{mol} \cdot \mathrm{kg}^{-1} \cdot \min ^{-1} p<0.01$, Fig. 2). 




Fig. 3. Correlation between fasting serum NEFA concentration and basal glucose oxidation rate



Fig. 4. Correlation between fasting serum NEFA concentration and lipid oxidation rate as determined from 50 to $80 \mathrm{~min}$ of insulin infusion

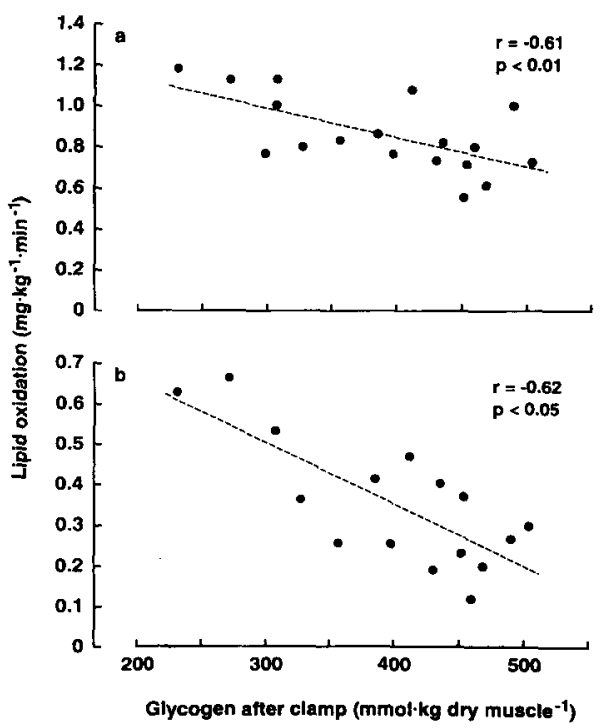

Fig. 5. Correlation between muscle glycogen content after insulin clamp and lipid oxidation rate in the basal state (upper panel) and during insulin infusion (lower panel). Lipid oxidation represents the mean of the three determinations during insulin infusion (all three measurements were obtained in 17 subjects only)
Fasting serum NEFA concentration was inversely related to the glucose oxidation in the basal state $(r=-0.80, p<0.001$, Fig. 3 ) or during the early part of insulin infusion (50 to $80 \mathrm{~min}: r=-0.76, p<0.001 ; 130$ to $160 \min : r=-0.54, p<0.05)$. At the end of the clamp, this association had vanished $(r=-0.31$, NS). No correlation was observed between non-oxidative glucose disposal and serum NEFA concentration at any time during insulin infusion. Fasting plasma triglyceride concentration was inversely related to total glucose disposal at the end of clamp $(r=-0.53, p<0.05)$. This correlation was accounted for by the non-oxidative glucose disposal $(r=-0.54, p<0.05)$. Plasma HDL cholesterol concentration at the end of insulin infusion was inversely related to total glucose disposal $(r=-0.57$, $p<0.01)$ and glucose storage $(r=-0.59, p<0.02)$ during the clamp. The basal HDL concentration did not correlate with total glucose disposal or glucose storage. The rise in plasma HDL during the clamp, however, was inversely related to total and non-oxidative glucose disposal at 50 to $80 \mathrm{~min}(r=-0.46, p<0.05$ and $r=-0.51, p<0.05$, respectively), and to total glucose disposal at 130 to $160 \mathrm{~min}(r=-0.46, p<0.05)$ and at the end of clamp $(r=-0.53, p<0.05)$.

Lipid oxidation. The lipid oxidation rate in the basal state correlated directly with the fasting NEFA concentrations $(r=0.57, p<0.05)$ and indirectly with the rate of glucose oxidation $(r=-0.47, p<0.05)$. During insulin infusion, the lipid oxidation rate fell from $0.87 \pm 0.04 \mathrm{mg} \cdot \mathrm{kg}^{-1} \cdot \mathrm{min}^{-1}$ to $0.15 \pm 0.05 \mathrm{mg} \cdot \mathrm{kg}^{-1} \cdot \mathrm{min}^{-1}$ $(p<0.001$, Fig. 2). The lipid oxidation rate from 50 to $80 \mathrm{~min}$ after insulin infusion correlated both with the fasting ( $r=0.82, p<0.001$, Fig. 4) and mean (between $0-240 \mathrm{~min})$ NEFA concentrations $(r=0.61, p<0.01)$. The lipid oxidation rate from 130 to $160 \mathrm{~min}$ during the clamp correlated with the NEFA concentration at $30 \min (r=0.60, p<0.01)$ and mean NEFA concentration $(r=0.63, p<0.01)$. Mean lipid oxidation during insulin infusion correlated inversely with mean oxidative glucose disposal $(r=-0.65, p<0.01)$, but not with mean total or non-oxidative glucose disposal. Lipid oxidation at the end of the clamp correlated negatively with LDL concentration at $180 \mathrm{~min}(r=-0.47$, $p<0.05)$ and at the end of clamp $(r=-0.61, p<0.01)$. The fall in LDL concentration correlated with the lipid oxidation at the end of the clamp $(r=0.71$, $p<0.001$ ).

Glycogen. Muscle glycogen concentration increased during insulin infusion from $317 \pm 25 \mathrm{mmol} / \mathrm{kg}$ dry muscle to $388 \pm 19 \mathrm{mmol} / \mathrm{kg}$ dry muscle $(p<0.05)$. The rise in muscle glycogen content correlated directly with the mean non-oxidative glucose disposal rate $(r=0.50$, $p<0.05)$ and indirectly with the basal glycogen concentration $(r=-0.72, p<0.001)$. Muscle glycogen concentration after the clamp correlated directly with the rate of glucose oxidation in the basal state $(r=0.57$, 
$p<0.05)$ and during insulin infusion $(r=0.56, p<0.05)$, and indirectly with the rate of lipid oxidation both in the basal state and during insulin infusion (Fig. 5). The mean NEFA concentrations (between 0-240 min) correlated inversely both with the rise in muscle glycogen during clamp $(r=-0.51, p<0.05)$ and with the glycogen content after clamp $(r=-0.70, p<0.01$, Fig. 6). The change in muscle glycogen concentration during insulin infusion was inversely related to plasma HDL cholesterol concentration as determined at the end of insulin clamp $(r=-0.70, p<0.002)$. Muscle glycogen content after clamp correlated negatively with the decline of both plasma total cholesterol $(r=-0.49$, $p<0.05)$ and LDL cholesterol $(r=-0.57, p<0.05)$.

Glycogen synthase. Glycogen synthase fractional activity before the clamp correlated inversely with basal muscle glycogen concentration $(r=-0.92, p<0.001)$ and directly with the rate of non-oxidative glucose disposal $(r=0.63, p<0.05)$ and the increase in muscle glycogen content $(r=0.75, p<0.01)$ during insulin infusion. A large range was observed in the glycogen synthase total activity in the basal state which correlated inversely with the basal lipid oxidation rate $(r=-0.53$, $p<0.05$, Fig. 7) and with the basal LDL concentration $(r=-0.53, p<0.05)$. Basal glycogen synthase fractional activity was inversely related to plasma HDL cholesterol concentration at the end of the insulin clamp $(r=-0.72, p<0.005)$. The glycogen synthase fractional activity increased during insulin infusion $(p<0.01)$, whereas the levels of glycogen synthase activity and glycogen synthase total activity did not change significantly (Table 1). The fall in LDL concentration during the clamp was negatively related to the glycogen synthase total activity $(r=-0.56, p<0.05)$ in muscle after the clamp. After insulin infusion, there was a close correlation between glycogen synthase activity and glycogen synthase total activity $(r=0.97, p<0.001)$.

\section{Discussion}

The major substrates for fuel homeostasis are NEFA and glucose. The contribution of each of these depends on the circumstances such as nutritional state, physical activity or the substrate availability. An elevation of NEFA decreases glucose utilization $[1,6-8,29,30]$, whereas interrelationships of these two substrates under physiologic conditions, such as in the fasting state, or under insulin-stimulated conditions are less well known. Moreover, data are scarce regarding the interaction of lipoproteins and glucose and NEFA metabolism. In the current study, we examined the relationship of glucose, lipid and lipoprotein metabolism in healthy man both in the total body and at the cellular level in the muscle. These examinations were done in the basal state after an overnight fast and during insulin stimulus.



Fig.6. Correlation between mean serum NEFA concentration (NEFA from 0 to $240 \mathrm{~min}$ ) and muscle glycogen content as determined at the end of insulin clamp

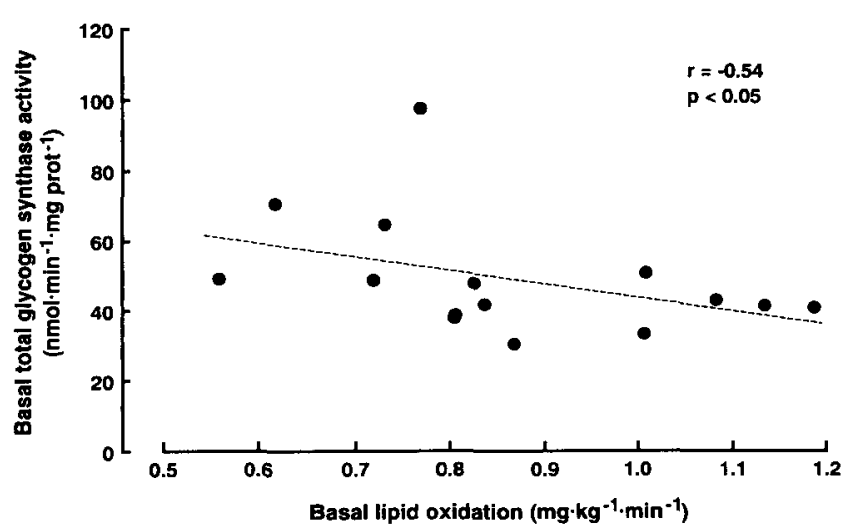

Fig.7. Correlation between lipid oxidation rate and the total glycogen synthase activity, both determined in the basal state

Table 1. Glycogen synthase activity $\left(\mathrm{nmol} \cdot \mathrm{min}^{-1} \cdot \mathrm{mg} \mathrm{protein}^{-1}\right)$ as determined in $\mathrm{m}$. quadriceps vastus lateralis in the basal state and after $240 \mathrm{~min}$ hyperinsulinaemia

\begin{tabular}{lcc}
\hline & Basal state & $\begin{array}{l}\text { After hyper- } \\
\text { insulinaemia }\end{array}$ \\
\hline $\begin{array}{l}\text { A. Glycogen synthase activity } \\
\text { (G 6-P 0.1 mmol/l) }\end{array}$ & $31.0 \pm 3.6$ & $36.5 \pm 3.8$ \\
$\begin{array}{l}\text { B. Glycogen synthase total } \\
\text { activity (G 6-P 10 mmol/l) }\end{array}$ & $49.3 \pm 4.4$ & $49.0 \pm 4.4$ \\
C. Fractional activity (A/B) & $0.63 \pm 0.03$ & $0.73 \pm 0.02^{\mathrm{a}}$ \\
\hline
\end{tabular}

${ }^{a} p<0.01$ vs basal. G 6-P, Glucose 6-phosphate

Regarding the interrelationship between lipid and glucose metabolism in the basal state, previous studies have demonstrated a negative correlation between insulin sensitivity and serum triglyceride concentration while either elevated [29] or in the normal range [31]. However, it has not been examined, whether triglycerides reduce non-oxidative or oxidative glucose disposal, or both. In the current study, fasting plasma triglyceride concentration was proportional to both in- 
sulin and $\mathrm{C}$-peptide levels suggesting that triglycerides cause insulin resistance. This association was further supported by a negative correlation between basal plasma triglyceride levels and total and non-oxidative glucose disposal at the end of the clamp. Our data thus indicate that in healthy subjects with plasma triglyceride concentration in the low normal range in a majority of subjects, triglycerides may have an inhibitory effect on non-oxidative glucose metabolism. This may occur via activation of lipoprotein lipase by insulin [32] leading to an ongoing release of NEFA from triglycerides providing fuel for lipid oxidation.

In the basal state, there was an inverse relationship between the rate of glucose oxidation and serum NEFA concentration, or between the rates of glucose and lipid oxidation. Similar associations have previously been shown both in healthy subjects during Intralipid infusion [29, 33-35] and in Type 2 diabetic patients with elevated NEFA concentrations $[8,35]$. In addition, basal lipid oxidation rate was proportional to the fasting NEFA concentrations, and during insulin infusion lipid oxidation correlated with the preceding NEFA concentration. Although a correlation as such does not prove a causal relationship, previous studies have clearly demonstrated that a lipid-heparin induced rise in serum NEFA concentrations can enhance lipid and reduce glucose oxidation $[33,34,36]$. Thus, our observations in healthy man under physiologic conditions suggest two interrelationships. First, the rates of glucose and lipid oxidation are inversely related: a stimulus in one leads to the reduction in the other. Second, NEFA concentration was related to both lipid and glucose oxidation but in an inverse manner. It is possible that either there is a direct relationship between glucose and lipid oxidation, or that both are regulated by a third factor, the availability of NEFA.

Whether lipid oxidation also inhibits non-oxidative glucose metabolism in the basal state is less clear [30, $33,34,36$. We observed an inverse relationship between basal muscle total glycogen synthase activity and lipid oxidation rate. During insulin stimulus, glycogen synthase fractional activity increased, whereas total glycogen synthase activity remained unchanged. Thus, insulin increased the enzyme activity without increasing its synthesis [37]. These data suggest that basal lipid oxidation may reduce total glycogen synthase activity in muscle cell, whereas its fractional activity is stimulated by insulin. However, rather than any other regulatory factor, the upper limit for the glycogen synthase activity is set by the total enzyme activity (i.e. enzyme protein content) as reflected by the close correlation between the two.

In the current study, the baseline glycogen synthase fractional activity was higher and the rise during insulin stimulus was less than we have previously reported in sedentary subjects $[16,30]$. Since basal fractional activity increases in proportion to physical fitness [12], a quite high maximal aerobic power in our subjects can explain their high glycogen synthase activity in the basal state. A small rise in the enzyme activity during insulin stimulus is probably a consequence of the high basal activity.

Regarding the interrelationship between lipid oxidation and glycogen synthesis, three interesting correlations were observed. First, in the basal state the lipid oxidation rate was inversely related to glycogen synthase total activity. Second, there was a close inverse correlation between lipid oxidation as determined either in the basal state or during insulin infusion, and muscle glycogen content after the clamp. Third, serum NEFA concentration during the clamp was inversely related to muscle glycogen content after the clamp. These correlations suggest that the greater the serum NEFA concentration and lipid oxidation rate, the less glycogen is formed both in the basal state and during insulin infusion.

However, the rise in muscle glycogen was closely and inversely related to the basal glycogen content. In addition, there was a close association between basal glycogen synthase fractional activity and muscle glycogen content. Thus, the major regulator of glycogen synthesis during insulin stimulus is probably muscle glycogen content in the basal state.

In agreement with previous studies $[36,38]$, we demonstrated a fall in total cholesterol and LDL cholesterol during hyperinsulinaemia. Several studies have suggested that insulin may stimulate the catabolism of LDL cholesterol. Insulin enhances LDL-receptor number [38] and there is a close correlation between the fractional catabolic rate of LDL apoprotein B and plasma insulin concentration [39]. Thus, the decrease in total cholesterol could be accounted for by a fall in LDL cholesterol due to its enhanced LDL-receptor mediated catabolism during insulin infusion. Serum NEFA concentrations both in the fasting state and during insulin infusion correlated with the fall in plasma total and LDL cholesterol. This raises a possibility that NEFA provide energy for the insulin-induced catabolism of LDL cholesterol.

During insulin infusion, serum HDL cholesterol levels have either decreased [38] or remain unchanged depending on the insulin concentration [32]. In the present study with an insulin infusion time longer than previously used $[32,40]$, HDL cholesterol concentration increased but only during the fourth hour of insulin infusion. Plasma HDL cholesterol concentration after 4-h insulin infusion was inversely related to total glucose disposal. Three associations suggest that the negative correlation between HDL cholesterol and glucose disposal can be accounted for by the glucose storage: HDL cholesterol concentration at the end of the clamp was inversely related to the rate of non-oxidative glucose disposal, to glycogen synthase fractional activity and to the rise in muscle glycogen content. The negative correlation between HDL cholesterol and glucose storage during prolonged insulin stimulus is perhaps 
not a direct one but explained by a third factor: the activation of adipose tissue lipoprotein lipase by insulin $[32,41]$. An inverse relationship between changes in the concentrations of LDL and HDL cholesterol could be due to different effects of insulin on the metabolism of the respective lipoprotein particles: a reduction in the clearance rate of the two major HDL proteins, lipoprotein A-I and A-II [42], and a decrease in the synthesis of lipoproteins containing apolipoprotein $B$, a major LDL protein [43].

In conclusion, our data suggest a major regulatory role for NEFA in the interrelationship between lipid and glucose metabolism both in the basal state and during insulin stimulus. The major hormone regulating these alterations in fuel homeostasis is insulin, which can simultaneously cause changes in lipoprotein kinetics. The regulation of this network is probably continuously adjusted according to the needs of the body and the nutritional status to provide an optimal fuel homeostasis for healthy man.

Acknowledgements. The skillful technical assistance of Ms R. Kärkkäinen and Ms E. Kostamo is appreciated. We are grateful to P. Kovanen, M. D. for critical reviewing of the manuscript. The study was supported by the Academy of Finland, Finnish Ministry of Education, Yrjö Jahnsson Foundation and Nordisk Insulin Foundation.

\section{References}

1. Randle PJ, Garland PB, Hales CN, Newsholme EA (1963) The glucose fatty acid cycle: its role in insulin sensitivity and the metabolic disturbances of diabetes mellitus. Lancet I: 785-789

2. Damsbo P, Vaag A, Hother-Nielsen O, Beck-Nielsen H (1991) Reduced glycogen synthase activity in skeletal muscle from obese patients with and without type 2 (non-insulin-dependent) diabetes mellitus. Diabetologia 34: 239-245

3. DeFronzo RA, Bonadonna RC, Ferrannini E (1992) Pathogenesis of NIDDM. A balanced overview. Diabetes Care 15: $316-368$

4. Eriksson J, Franssila-Kallunki A, Ekstrand A et al. (1989) Early metabolic defects in persons at increased risk for noninsulin dependent diabetes mellitus. N Engl J Med 321: 337 343

5. Ferrannini E, Buzzigoli G, Bonadonna R et al. (1987) Insulin resistance in essential hypertension. N Engl J Med 317: 350357

6. Yki-Järvinen H, Puhakainen I, Koivisto VA (1991) Effect of free fatty acids on glucose uptake and nonoxidative glycolysis across human forearm tissues in the basal state and during insulin stimulation. J Clin Endocrinol Metab 72: 1268-1277

7. Nuutila, P, Koivisto VA, Knuuti J et al. (1992) Glucose-free fatty acid cycle operates in human heart and skeletal muscle in vivo. J Clin Invest 89: 1767-1744

8. Groop LC, Bonadonna RC, Del Prato Set al. (1989) Glucose and free fatty acid metabolism in non-insulin-dependent diabetes mellitus: evidence for multiple sites of insulin resistance. J Clin Invest 84: 205-213

9. Vaag A, Henriksen JE, Beck-Nielsen H (1992) Decreased insulin activation of glycogen synthase in skeletal muscles in young nonobese Caucasian first-degree relatives of patients with non-insulin-dependent diabetes mellitus. J Clin Invest 89: 782-788

10. Thorburn AW, Gumbiner B, Bulacan F, Brectel G, Henry RR (1991) Multiple defects in muscle glycogen synthase activity contribute to reduced glycogen synthesis in non-insulin dependent diabetes mellitus. J Clin Invest 87: 489-495

11. Schalin-Jäntti C, Härkönen M, Groop LC (1992) Impaired activation of glycogen synthase in people at increased risk for developing NIDDM. Diabetes 41: 598-604

12. Taylor AW, Thayer R, Rao S (1972) Human skeletal muscle glycogen synthase activities with exercise and training. Can J Physiol Pharmacol 50: 411-415

13. DeFronzo RA, Tobin JD, Andres R (1979) Glucose clamp technique: a method for quantifying insulin secretion and resistance. Am J Physiol 237: E214-E224

14. Yki-Järvinen $H$, Koivisto VA (1986) Natural course of insulin resistance in type I diabetes. $\mathrm{N}$ Engl J Med 315:224-230

15. Koivisto VA, Yki-Järvinen H, Puhakainen I, Virkamäki A, Kolaczynski J, DeFronzo RA (1990) No evidence for isotope discrimination of tritiated glucose tracers in measurements of glucose turnover rates in man. Diabetologia 33:168-173

16. Yki-Järvinen H, Sahlin K, Ren JM, Koivisto VA (1990) Localization of rate-limiting defect for glucose disposal in skeletal muscle of insulin-resistant type I diabetic patients. Diabetes 39: 157-167

17. Vuorinen-Markkola H, Koivisto VA, Yki-Järvinen H (1992) Mechanisms of hyperglycemia-induced insulin resistance in whole body and skeletal muscle of type 1 diabetic patients. Diabetes 41: 571-580

18. Ferrannini E (1987) The theoretical basis for indirect calorimetry: a review. Metabolism 37: 287-301

19. Hornbrook KR, Birch HB, Lowry OH (1966) The effects of adrenalectomy and hydrocortisone on rat liver metabolites and glycogen synthase activity. Mol Pharmacol 2: 106-116

20. Lowry OH, Rosebrough NJ, Farr AL, Randall RJ (1951) Protein measurement with the Folin phenol reagent. J Biol Chem 193: 265-275

21. Borg, G (1962) Physical performance and perceived exertion. Gleerup, Lund, pp 1-62

22. Desbuquois B, Aurbach GD (1971) Use of polyethylene glycol to separate free and antibody-bound peptide hormones in radioimmunoassays. J Clin Endocrinol Metab 33: 732-738

23. Heding LG (1975) Radioimmunological determination of human C-peptide in serum. Diabetologia 11:541-548

24. Miles J, Glasscock R, Aikens J, Gerich J, Haymond M (1983) A microfluorometric method for the determination of free fatty acids in plasma. $J$ Lipid Res 24: 96-99

25. Siedel J, Hägele EO, Ziegenhorn J, Wahlefeld AW (1983) Reagent for the enzymatic determination of serum total cholesterol with improved lipolytic efficiency. Clin Chem 29: 1075-1080

26. Finley PR, Schifman RB, Williams RJ, Lichti DA (1978) Cholesterol in high density lipoprotein: use of $\mathrm{Mg}^{2+} /$ dextran sulphate in its enzymic measurement. Clin Chem 26:931-933

27. Friedewald WT, Levy RI, Fredrickson DS (1972) Estimation of the concentration of low-density lipoprotein cholesterol in plasma, without use of the preparative ultracentrifuge. Clin Chem 18: 499-502

28. Bergmeyer HU (1974) Metoden der enzymatischen Analyse, 3. Auflage, Bd. II. Verlag Chemie, Weinheim, p 1878

29. Ferrannini E, Barrett EJ, Bevilaqua S, DeFronzo RA (1989) Effect of fatty acids on glucose production and utilization in man. J Clin Invest 72: 1737-1747

30. Saloranta C, Koivisto VA, Widen E et al. (1993) Contribution of muscle and liver to the glucose/fatty acid cycle in man. Am J Physiol 264: E599-E605 
31. Tobey TA, Greenfield M, Kreamer F, Reaven GM (1981) Relationship between insulin resistance, insulin secretion, very low density lipoprotein kinetics and plasma triglyceride levels in normotriglyceridemic man. Metabolism 30: 165-171

32. Yki-Järvinen $\mathbf{H}$, Taskinen $\mathrm{M}-\mathrm{R}$, Koivisto VA, Nikkilä EA (1984) Response of adipose tissue lipoprotein lipase activity and serum lipoproteins to acute hyperinsulinaemia in man. Diabetologia 27: 364-369

33. Lillioja S, Bogardus C, Mott DM, Kennedy AL, Knowler WC, Howard BV (1985) Relationship between insulin-mediated glucose disposal and lipid metabolism in man. J Clin Invest $75: 1106-1115$

34. Lee KU, Lee HK, Koh CS, Min KH (1988) Artificial induction of intravascular lipolysis by lipid-heparin infusion leads to insulin resistance in man. Diabetologia 31: 285-290

35. Felber J-P, Ferrannini E, Golay A (1987) Role of lipid oxidation in the pathogenesis of insulin resistance in obesity and type II diabetes. Diabetes 36: 1341-1350

36. Godsland IF, Crook D, Walton C, Wynn V, Oliver MF (1992) Influence of insulin resistance, secretion and clearance on serum cholesterol, triglycerides, lipoprotein cholesterol and blood pressure in healthy men. Arteriosclerosis Thrombosis 12: $1030-1035$
37. Larner J (1988) Insulin-signaling mechanisms. Lessons from the old testament of glycogen metabolism and the new testament of molecular biology. Diabetes 37: 262-275

38. Chait A, Bierman EL, Albers J (1979) Low-density lipoprotein receptor activity in cultured human skin fibroblasts. $J$ Clin Invest 64: $14 \mathrm{~A}$

39. Kissebah AH, Alfarsi S, Evans DJ, Adams PW (1983) Plasma low density lipoprotein transport kinetics in non-insulin dependent diabetes mellitus. J Clin Invest 71: 655-667

40. Sadur CN, Eckel RH (1983) Insulin-mediated increases in the HDL cholesterol/cholesterol ratio in humans. Arteriosclerosis 3: 339-343

41. Vuorinen-Markkola $H$, Yki-Järvinen $H$, Taskinen $M-R$ (1993) Lowering of triglycerides by gemfibrozil affects neither the glucoregulatory nor antilipolytic effect of insulin in type 2 (non-insulin-dependent) diabetic patients. Diabetologia 36: $161-169$

42. Taskinen M-R, Kahri J, Koivisto VA, Packard CJ (1992) Metabolism of HDL apolipoprotein A-I and A-II in type 1 (insulin-dependent) diabetes mellitus. Diabetologia 35: $347-$ 356

43. Rosenstock J, Vega GL, Raskin P (1988) Effect of intensive diabetes treatment on low-density lipoprotein apolipoprotein $\mathbf{B}$ kinetics in type 1 diabetes. Diabetes $37: 393-397$ 